\title{
Humanização como Ferramenta de Construção de Autonomia na Adoção de Estilo de Vida Saudável em Grupos de Trabalhadores
}

\author{
Fonseca, Isabela Kelley Lazaro; Barata, Jaqueline Marques Lara \\ Faculdade de Ciências Medicas de Minas Gerais — isabela.kelley@gmail.com
}

Introdução: Humanização da assistência em saúde busca dar espaço a voz tanto do usuário quanto a do profissional de saúde, onde há uma construção de uma rede de diálogo e de confiabilidade, que tem como resultado a promoção de ações que garantirão os direitos de ambas as partes através de um posicionamento que respeita as particularidades de cada indivíduo (Oliveira; COLLET; Viera 2006). nos dias de hoje, tanto o consumo de cigarro quanto o consumo excessivo de alimentos, são causas de mortes e adoecimentos evitáveis no Brasil e no mundo. Nesse sentido, quando os usuários vivenciam situações de exposição a agravos é necessário que os profissionais de saúde saiam de uma conduta prescritiva e promovam o diálogo, o que pode ter como consequência a redução os índices de morbimortalidade, pelo fato de exporem suas dificuldades vivenciadas nos processos. Objetivo: Trata-se se um projeto que visou a implantação de grupos com o enfoque na reeducação alimentar e na cessação do tabagismo através de estratégias humanizadas, que buscam a qualidade de vida dos trabalhadores de um hospital público localizado na cidade de Belo Horizonte. Método: Estudo descritivo, do tipo relato de experiência, sobre os projetos "Abordagem Humanizada no Processo de Cessação do Tabagismo" e "Abordagem Humanizada no processo de reeducação alimentar". Os encontros dos grupos de cessação de tabagismo e reeducação alimentar aconteceram em seis reuniões localizadas no auditório do hospital. Cada grupo foi composto por 15 participantes previamente inscritos, sendo utilizado como forma de abordagem a escuta ativa, dinâmicas, debates, apresentações de assuntos e informações relevantes para os participantes do grupos. Resultados: o reflexo da saúde dos trabalhadores influencia na qualidade do acolhimento e cuidado prestados, seja direta ou indiretamente. Nesse sentido, foi proposto aos servidores do Hospital os grupos de cessação ao tabagismo e reeducação alimentar, visando o incentivo à qualidade de vida através de mudanças de hábitos. Isso traz bons resultados não apenas à instituição, mas a cada ser humano envolvido em seu próprio processo de recuperação, resgate pela leveza e bem estar, através da reflexão e reconhecimento das suas potencialidades. Conclusão: a forma de abordagem humanizada dentro de grupos operativos, colaborou não só com a mudança de hábitos, mas também com a melhoria da auto estima dos participantes, pois foi mostrado a cada um deles a sua força e importância dentro do próprio do processo de mudança e construção de autonomia.

Fonseca, Isabela Kelley Lazaro; Barata, Jaqueline Marques Lara. Humanização como Ferramenta de Construção de Autonomia na Adoção de Estilo de Vida Saudável em Grupos de Trabalhadores. In: Anais do Congresso Internacional de Humanidades \& Humanização em Saúde [= Blucher Medical Proceedings, num.2, vol.1]. São Paulo: Editora Blucher, 2014. ISSN 2357-7282

DOI 10.5151/medpro-cihhs-10637 